\title{
A Conceptual Analysis of Metaphors Engendering HIV and AIDS- Related Stigma and Discrimination in Kisii County, Kenya
}

\author{
Geoffrey Mokua Maroko \\ Department of Languages and Linguistics \\ Machakos University, Machakos \\ Email: gmaroko@mksu.ac.ke \\ Gladys Nyamoita Mokua \\ Department of Pharmacognosy, Pharmaceutical Chemistry \& Pharmaceutics \\ Kenyatta University, Nairobi \\ Email: mokuag@yahoo.com \\ Augustus Onchari Nyakundi \\ Department of Communication Studies \\ Chuka University, Chuka \\ Email: augustusosoro@gmail.com \\ Meshack Ondora Onyambu \\ Department of Pharmacognosy, Pharmaceutical Chemistry \& Pharmaceutics \\ Kenyatta University, Nairobi \\ Email: mesh10200@yahoo.com
}

\begin{abstract}
Metaphors are mapped across two conceptual domains where A is B. Metaphorical expressionsare defined by dimensions including novelty, conventionality, abstractness and concreteness. The AbaGusii of Western Kenya is a highly conservative community of Bantu speakers of Western part of Kenya. They view HIV and Aids as taboo that cannot be the subject of discussion in public. Hence, People Living with HIV (hereafter PLHIV) are stigmatized and discriminated. The purpose of this paper is to analyse the metaphorical words and concepts that engender HIV and Aids-related stigma and discrimination in Kisii County. Descriptive narratives were elicited from HIV support providers using focus group discussions and follow-up interviews. The narratives were analysed in terms of five attributes of stigma and discrimination within the conceptual metaphor theory. Results revealed some culturally ingrained metaphors that evoke stigma and discrimination. The paper advocates for language management efforts using success stories in HIV and Aids management to construct positive messages to counter the negative metaphors.
\end{abstract}

Keywords: Metaphor, Stigma, Discrimination, Conceptual domain, Mapping

\section{INTRODUCTION}

According to the $\mathrm{MoH}$ (2014), the number of new HIV infections remains high with close to 101,560 new infections reported annually. This trend has made HIV the third largest epidemic in Sub-Saharan Africa. It is estimated that 1.6 million people are living with HIV in Kenya. One of the major barriers identified in access to HIV testing and treatment, care and support services is stigma and discrimination. Stigma is viewed as the devaluation of people living with or are associated with HIV and Aids while discrimination is what happens when someone is treated in an unjust, unfair or prejudicial way, often on the basis of belonging to a particular group.
According to statistics in the Department of Health in Kisii County, the leading causes of morbidity and mortality are respiratory tract infections, HIV and Aids, perinatal conditions, Tuberculosis, malaria, skin conditions, accidents and diarrheal diseases. The western parts of the country including Kisii County are the most affected. The County ranks fifth among the most affected Counties after Homabay, Siaya, Kisumu and Migori respectively. The female gender is apparently more susceptible to HIV and Aids than their male counterparts. According to a report by the National Aids Control Council, access to anti-retroviral treatment is highest in UasinGishu County averaging at $144 \%$ but ranks lowly in Kisii County at only $48 \%$. Accordingly, ART is being 
received by less adult individuals than expected in the top 5 counties (Homabay, Siaya, Kisumu, Migori, Kisii and Turkana) with high prevalence rates. The number of those in ART dropped from 14509 in 2012 to 11467 in 2016 (Kisii County, Health at a Glance Report at their Website). Partly, this can be attributed to entrenched stigma and discrimination surrounding HIV/Aids in Kisii County.

According to UNAIDS (2017), stigma and discrimination is creating barriers to accessing HIV prevention, testing and treatment services and putting lives at risk. The report shows that people living with HIV who experience high levels of HIV-related stigma are more than twice as likely to delay enrolment into care as people who do not perceive HIV-related stigma. In Kisii County, people living with HIV avoid going to health facilities for support for fear of having their status disclosed or of suffering further stigma and discrimination based on their HIV status. A report by UNAIDS (2017) indicates that across 19 countries with available data, one in five people living with HIV avoided going to a clinic or hospital because they feared stigma or discrimination related to their HIV status. When people living with HIV wait until they are very ill before seeking help, they are less likely to respond well to antiretroviral therapy. The report asserts that in order to reach all people living with, or at risk of, HIV and to link them with HIV prevention and treatment services, the world must step forward and confront discrimination.

The Kenya HIV and AIDS Prevention and Control Act (2006) safeguards the rights of People Living with HIV (PLHIV), promotes voluntary HIV testing, confidentiality and privacy, non-discrimination in employment and education, and unfettered access to quality healthcare services. It also calls for the integration of HIV programs in all sectors. Despite this, PLHIV are often confronted with the problem of stigma and discrimination.

The Kisii people (also known as the AbaGusii tribe) form a Bantu ethnic group who occupy the Kisii highlands in Nyanza, Western Kenya. AbaGusii constitute the sixth largest ethnic group in Kenya, comprising about seven percent of the national population. EkeGusii is the ethnic language of AbaGusii. According to Guthrie (1964), EkeGusii is labeled zone E42 narrow East African Bantu language group in Kenya. The language has two dialects; Rogoro and Maate, but we used the Rogoro dialect which has more speakers and considered to be more prestigious (Bosire, 1993).
AbaGusii belong to two of the 47 Counties in Kenya namely; Nyamira and Kisii. The estimated population in Kisii County by 2018 was $1,406,043$ comprising of 674,901 males (48\%) and 731,142 females (52\%) (KNBS projection from 2009 census). With the population growth rate of $2.2 \%$ per annum, it is estimated that by the year 2022, the total population will be $\approx$ $1,533,977$. AbaGusii believed in a supreme god called Engoro, whom was understood to have created the universe and was the source of all life.

AbaGusii culture identifies four rites of passage namely Okoiborwa (Birth), Ogachia mache motwe (Initiation), Okonywoma (Marriage) and Ogokwa (Death). Each of these rites was traditionally observed under very strict codes. Any violation of the codes was taboo and attracted serious repercussions including generational curses and even death. Sex is a taboo subject among AbaGusii with anything associated with it being communicated euphemistically or metaphorically. Sex before marriage or out of wedlock was considered taboo. It attracted a type of curse (amasangi) which led to the death of the perpetrator, the victim or their close relatives such as spouses and children. The society allowed sex among traditionally wedded couples. AbaGusii traditions socialised men to marry many wives through metaphoric expressions in the male circumcision song (esimboore). Widows were also allowed to engage in sexual relations with an officially anointed person closely related to the husband such as a brother or a cousin. This was traditionally referred to as ogosoa nyomba ('entering the house'). Death was considered an "unnatural" event brought about by witchcraft (oborogi) or unhappy ancestors (chisokoro) for violating the norms and customs.

AbaGusii believed in medicine men and women and also in the spirits of their ancestors. It is a common practice that a large population of PLHIV visit traditional health practitioners and use traditional medicine especially for the management of HIV/Aids. Some of the reasons for shunning conventional facilities for comprehensive care include stigma and discrimination, traditional beliefs, cultural barriers, and lack of confidentiality. This therefore indicates a clear need to explore ways in which traditional medicine practitioners can be used more effectively to facilitate delivery of both western biomedical innovations and traditional therapies.

The MoH Report (2014, p.21) outlines a raft of recommendations to address the problem of stigma and discrimination among them being the need to conduct regular studies to 
measure,monitor the levels and underlying causes ofHIV related stigma and discrimination and providelocalised evidence-based interventions to addressthe situation. This paper hypothesizes that stigma and discrimination are anchored in the linguistic metaphors that are used to depict HIV and Aids. Therefore, the aim of the paper is to establish the forms of HIV and Aids-related stigma and discrimination, identify the linguistic metaphors that entrench stigma and discrimination, and finally to unpack their meanings and connotations with a view to highlighting how they instigatestigma and discrimination in PLHIV. The paper recommends a shift from these metaphors occasioned by campaign mechanisms that demystify PLHIV.

From the non-linguistic paradigm, Wamalwa, Neyole, Poipoi \& Bitok (2015) carried out a study to determine HIV prevention knowledge and knowledge gaps among PLHIVs in Kisii County, Western Kenya. A total 340 PLHIVs across 9 health facilities and 6 Key informants, mainly HIV managers and programmers were interviewed. We found high generalized knowledge among PLHIVs on HIV prevention, as well as on condom use, abstinence and faithfulness to a partner as prevention methods. We however found low knowledge levels on emerging biomedical prevention methods, including treatment as prevention. Similarly, despite high knowledge levels on Mother to Child Transmission (MTCT), few PLHIVs know exact phases in which MTCT can occur pregnancy, delivery and breast feeding -with males, those depending on kin as primary income source and PLHIVs attending higherlevel facilities least likely to have this knowledge. Media, health workers and HIV campaigns remain the most important communication channels for PLHIVs as regards HIV information, while peers are an important information source for males. Our observations highlight the need to further promote knowledge of various HIV prevention methodologies, especially emerging prevention methods, among specific PLHIVs sociodemographic groups that exhibit low knowledge levels.

In another study, Wamalwa et al (2015) sought to establish condom use determinants and practices among people living with HIV (PLHIVs) in Kisii County, Kenya. They interviewed 340 PLHIVs and 6 health workers. Findings revealed that although most PLHIVs had correct knowledge and approved condoms as effective for HIV prevention, consistent use and condom use at last sex were notably low especially among PLHIVs aged 18 - 24, those who de- pended on remittances from kin as main source of income, as well as during sex with secondary and casual partners. This study notes that knowledge on various benefits of using condoms is associated with enhanced condom use practices. Non-disclosure of HIV status to secondary and casual partners remains a key barrier to condom use among PLHIVs. Our observations highlight the need to further promote condom use among specific PLHIVs socio-demographic groups who continue to exhibit low condom use rates.

Feyissa, Abebe, Germa \& Woldie (2012) investigated stigma and discrimination against PLHIV by healthcare providers in Jimma zone, Southwest Ethiopia. The study focused on sociodemographic characteristics, HIV knowledge, perceived institutional supportand HIV-related stigma and discrimination. The study revealed that testing and disclosing test results was done without consent without the consent of the people involved. The study also indicated that clients found to be HIV positive were not only denied treatment but were unnecessarily referred to other healthcare institutions. It emerged that higher levels of stigma and discrimination against PLHIV were associated with lack of in-depth knowledge on HIV and orientation to policies on stigma and discrimination. The study recommends that health managers should ensure institutional support through availing of clear policies and guidelines and the provision of appropriate training on the management of HIV and Aids.

To improve outcomes in HIV and Aids response, this paper analyses the metaphors entrenching HIV and Aids-related stigma and discrimination in the County.

The conceptual metaphor theory (Lakoff and Johnson, 1980) provides a framework for discussing the metaphors engendering HIV and Aids interventions in Kisii County. It has its beginnings in Lakoff and Johnson's book, Metaphors We Live By (1980). The theory takes metaphor as a conceptual tool for structuring, restructuring and even creating reality. A conceptual metaphor is understanding one domain of experience (that is typically abstract) in terms of another (that is typically concrete). Thus, a conceptual metaphor can be viewed both as a process and as a product. The cognitive process of understanding a domain is the process aspect of metaphor, while the resulting conceptual pattern is the product aspect.

Metaphors have the following features. First, they are all pervasive (Lakoff and Johnson, 1980). This means that metaphors are ubiquitous as they can be found on TV, radio, dictionaries, routine spoken discourses, in newspapers, in 
genres and, in language in general. According to McGlone(2007)linguistic manifestations can prove the presence of conceptual metaphors. Second, the theory underscores the claim for systematic mappings between two conceptual domains. In this way, a conceptual metaphor is a systematic set of correspondences between two domains of experience. This implies that one domain mirrors another.

Thirdly, conceptual metaphor theory allows movement from the concrete domain to the abstract domain. A distinction is made between the source domain and the target domain, representing concrete domain and abstract domain respectively. In the example LIFE IS A JOURNEY (Lakoff and Johnson, 1980), journey is more concrete (source domain) than life (target domain). In this way, the theory proposes that more physical domains typically serve as source domains for more abstract targets. Fourth, metaphors occur in thought. There is a tendency to use metaphors not only to speak about certain aspects of the world but also to think about them. Conceptual metaphor theory makes a distinction between metaphors; that is, exemplars of conceptual patterns we rely on in our daily living to think about aspects of the world. For instance, what people will say about HIV and Aids is a reflection of their thinking. The thinking is shaped by society, culture and is expressed metaphorically through language. Fifth, conceptual metaphors are grounded in the sense that the source domain is paired with a particular target domain. In other words, there is a similarity or resemblance between two things or events. This paper makes an effort to establish how comparisons involving HIV and Aids and real life as socially constructed could be entrenching stigma and discrimination thereby rendering HIV and Aids interventions ineffective. In sum, it can be observed that the Conceptual Metaphor Theory as postulated by Lakoff and Johnson $(1980,2008)$ ascribes to the conceptual and the linguistic dimensions of metaphor.
There has been a spate of interest by research communities in establishing the different modalities of metaphor expression, and in particular the visual modality. Such communities include marketing theory (e.g. Phillips \& McQuarrie, 2004; Ng \& Koller, 2013), cognitive psychology (e.g. van Weelden, Maes, Schilperoord \& Swerts, 2012), linguistics (e.g. Perez-Sobrino, 2016) and media (e.g. Forceville, 2005).

Onchoke \& Wen (2017) conducted a cognitive analysis of woman metaphors in EkeGusii language. The study indicates that a woman is perceived as an object, a plant or an animal. The study also shows that a woman can be depicted by the appropriate behavior she exhibits based on values such as immorality, selfishness, beauty, ugliness, harshness, talkativeness, age, and faithfulness. The cultural background plays an important role in the conceptualization and interpretation of these metaphors. The study recommends more research of metaphors in other languages to enable comparisons.

Another theoretical framework in this paper defines and categorizes stigma and discrimination $(\mathrm{MoH}, 2014)$. The framework identifies five categories of stigma and discrimination based on a stigma index study in Kenya. The purpose of the survey was to guide interventions and policies to address HIV related stigma and discrimination in order to enhance the quality of life of PLHIV. The study identified five forms of stigma and discrimination and established a composite stigma rating of $45.16 \%$ in Kenya which was rated high. Details of the survey are summarized in Table 1.

Patterns in Table 1 indicate that three forms of stigma have recorded very high incidences. These are: experience of stigma's negative effects (74), concern about disclosure of HIV status (70), and judgment or blame of PLHIV (47). Though people fearful of contracting HIV from noninvasive contact with PLHIV and PLHIV who experience stigma's negative

Table 1. Stigma and Discrimination Index by Category

\begin{tabular}{lllc}
\hline Form of stigma & Score & Unit Value & Index \\
\hline PLHIV who are concerned about disclosing their status & 70.00 & 20.00 & 14.05 \\
People fearful of contracting HIV from non-invasive contact with & 18.00 & 20.00 & 3.60 \\
PLHIV & & & \\
People who judge or blame PLHIV for their illness & 47.00 & 20.00 & 9.36 \\
PLHIV who think they have experiences stigma in the last year & 17.00 & 20.00 & 3.44 \\
PLHIV who experience stigma's negative effects on themselves, the & 74.00 & 20.00 & 14.70 \\
family, and the community & & & 400.00 \\
Composite stigma rating for Kenya & & & 45.16 \\
\hline
\end{tabular}


effects recorded lower scores of 18 and 17 respectively, the forms can still impede HIV and Aids mitigation efforts profoundly. The table shows a composite stigma rating for $45.16 \%$. In the study reported in this paper, the five categories will be used to classify the metaphors that entrench HIV-related stigma and discrimination.

Since stigma and discrimination have been found to undermine effective implementation of HIV and Aids interventions in Kisii County, this paper delves into metaphors that underpin counter-productive cultural mindsets. This could provide a targeted frontier in HIV and Aids response.

\section{METHODOLOGY}

\section{Research Site}

The study was carried out in Kisii County of Western Kenya. The County is among the 47 counties in Kenya. It neighbours Nyamira County to the North East, Narok to the South, Homabay and Migori to the West. Kisii County lies between latitude $30^{\circ}$ and $10^{\circ} \mathrm{S}$ and longitude $35^{\circ} 38^{\prime}$ and $35^{\circ}$ East. The County covers a total area of $1,317.5 \mathrm{~km}^{2}$. It is divided into nine (9) Sub-Counties namely Bobasi, Bomachoge, Borabu, Bonchari, South Mugirango, Kitutu Chache North, Kitutu Chache South, Nyaribari Masaba, Nyaribari Chache and Bomachoge Chache (Figure 1).

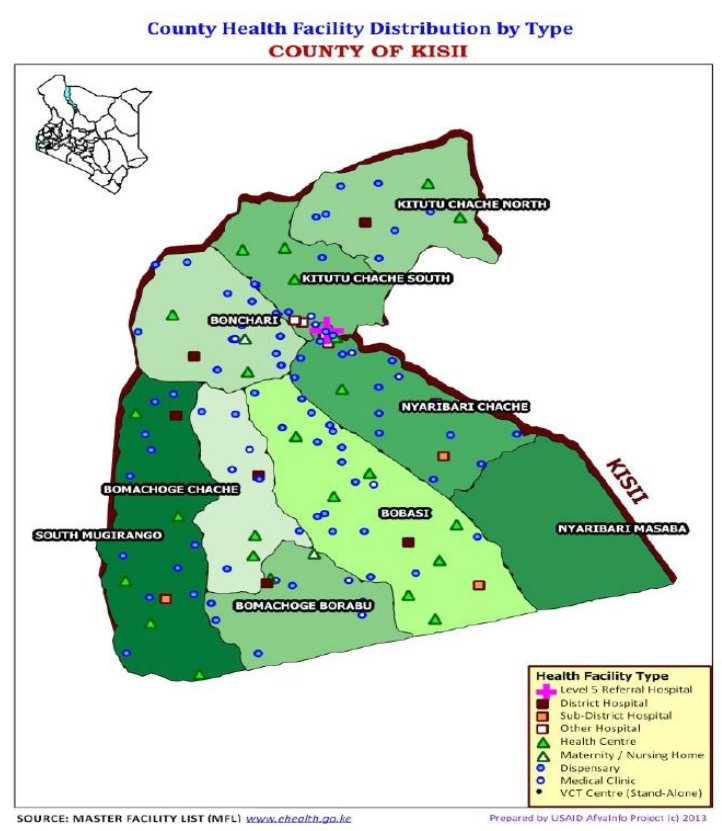

Figure 1. Kisii County Map

\section{Ethical considerations}

To anchor the study reported in this paper within acceptable ethical standards, the research proposal, data collection instruments and the informed consent form were reviewed and approved (Approval Number CU/IERC/NCST/18/53) by a registered Institutional Ethics Committee. The study was then issued with Research Permit Number NACOSTI/P/18/50245/24190 by the National Commission for Science, Technology \& Innovation. Before data collection, all respondents were fully debriefed about the purpose of the study and asked to sign an informed consent form. They were assured of anonymity and confidentiality.

\section{Sampling}

The population of the study comprised people living with HIV (PLHIV) working as peer counsellors in HIV Testing Centres (HTCs) and Comprehensive Care Centres (CCCs) in selected health facilities in the County. The study population also included women living with HIV but have never transmitted HIV to their children during breastfeeding. This category is called mentor mothers and leaders of support groups in the Prevention of Mother-to-Child Transmission (PMTCT) units in health facilities in the County. The study population also included HIV Testing Service (HTS) counsellors, and clinicians. To select these groups from selected health facilities, purposeful sampling method was used. This method involves identifying and selecting individuals or groups of individuals that are especially knowledgeable about or experienced with a phenomenon of interest (Cresswell \& Clark, 2011). The study was interested in participants knowledgeable about HIV and Aids-related stigma and discrimination and also willing and able to communicate their experiences and opinions in an articulate, expressive, and reflective manner. Therefore, those who provided informed consent and produced metaphor-rich cases during interviews and focus group discussions were identified and selected as the study sample.

\section{Data Collection}

One method of data collection employed in this study was the focus group discussion. Ochieng, Wilson, Derrick, Mukherjee (2018) have recommended this method when there is need to obtain data from a purposely selected group of individuals rather than from a statistically representative sample of a broader population. This 
method was therefore deemed suitable for gaining an in-depth understanding of the metaphorical construction of stigma and discrimination in HIV and Aids interventions in Kisii County.

Support groups in the County included people living with HIV and Aids of between 10 and 30 members organized according to such variables as gender, age group, and HIV viral load. The groups also included peer counsellors, HIV Testing Service counsellors, mentor mothers and clinicians. The focus group discussions took place during monthly meetings in facilities by support groups as they receive their anti-retroviral therapy (ART). Introducing ourselves as researchers from various universities and after discussing the informed consent form with them, they allowed us to participate in their discussion and collect the data we needed in the process. Two active focus groups (the ante natal, lactating mothers) were used for discussions. Themes covered included people's perception of HIV and Aids, disclosure of their HIV status, relationships at home, coping with medication, and hygiene.

To complement focus group data, followup interviews involving caregivers of orphaned and vulnerable children, clinicians, mentor mothers and peer counsellors were carried out. DeJonckheere \& Vaughn (2019) argue that follow-up interviews present an opportunity for collecting open-ended data and exploring participant thoughts, feelings and beliefs about a particular topic and delving deeply into personal and sometimes sensitive issues. It was therefore better suited to elicit sensitive HIV and Aids information in unfolding and iterative interactions between us and the interviewees.

Each of us interviewed at least a care giver, clinician, mentor mother and peer counsellor separately guided by a pre-determined open ended interview guide. The interview allowed the respondents to narrate anecdotes coloured by metaphors engendering stigma and discrimination. We also recorded the interview sessions. Later on, each of us transcribed audio texts followed by plenary sessions for joint selection of texts bearing HIV and Aids metaphors on stigma and discrimination. This exercise gave us an opportunity to build consensus on metaphoric words and expressions and the stigma/discrimination meanings they espouse.

\section{Data analysis}

Analysing focus group discussion and follow-up interview data is usually determined by the research question and the purpose for which the data are collected. Focus group discussion and follow-up interviews were used for an indepth exploration of metaphors instigating HIV and Aids stigma and discrimination about which little is known. For such exploratory research therefore, a simple descriptive narrative approach to analysis was quite appropriate.

The first level of analysis comprised qualitative processing and categorizing of data on stigma and discrimination according to the classification scheme by $\mathrm{MoH}$ (2014). This was followed by categorization and synthesis of metaphoric words and expressions with HIV and Aids stigma and discrimination connotations into source and target domains in line with the conceptual metaphor theory (Lakoff and Johnson, 1980). The outcome was used to present a descriptive narrative.

\section{RESULTS AND DISCUSSION}

Data from this study revealed metaphors whose underlying conceptual logic matches the cultural beliefs and psyche of the AbaGusii people of Western Kenya. The following descriptive narrative adopts the schema by $\mathrm{MoH}$ (2014) where stigma and discrimination is classified into concern about disclosure of HIV status, judging and/or blaming PLHIV for illness, PLHIV who have experienced stigma in the past and PLHIV who have experienced stigma in the past. The categories are discussed stepwise.

\section{Concern about disclosure of HIV status}

One of the ways HIV and Aids entrench stigma and discrimination among the people is through concern about disclosure of HIV status. People living with the condition do not want their HIV status to be known by others including their intimate partners. Accounts gathered from respondents revealed that knowledge of one's HIV status could lead to either rejection or isolation. For instance, in one of the Level 4 medical facilities in Kisii County, an HIV Testing Service counselor attested that it is hard for people living with HIV to disclose their HIV status or the possibility of infecting others. Her narration is captured in Text 1:

\section{TEXT 1}

"We have a case where a 19-year-old is very bitter with the mother for transmitting HIV to him. The boy contracted HIV through mother-tochild transmission. The mother has been picking ARVs for the boy without explaining to him that he is HIV positive. The boy only discovered recently through provider notification. As a result, 
the boy doesn't want to see his mother. When we asked her why she couldn't disclose the boy's condition to him, she said: Tintageti o'mwana o'ne aniinkoorwe n'abande e'sukuru. (I don't want my child to be isolated by others in school)"

In the italicized text, o'mwana o'ne (my child) and a'ninkoorwe (be abandoned and discriminated) suggest that a PERSON LIVING WITH HIV IS A PARIAH. This means that PLHIVcannot mingle with uninfected people. They ought to be isolated at all times.

Similarly, owing to the presumptive stigma and discrimination associated with HIV and Aids, a woman is in denial and does not know how to disclose her HIV status to her spouse in a Level 3 hospital. An HIV testing counsellor recounted the case as follows:

\section{TEXT 2}

"A woman tested positive in this clinic. She doesn't know how to disclose this outcome to her husband whom she claimsis very hostile. She said: Aise komanya ng'a ni'ndwarete nigo a'gonseeria. (Should he know that I am sick, he will send me away from my matrimonial home). She has therefore refused to own the results. She is therefore unable to begin medication for fear of being discovered by the husband. As a result, she has become weak and anaemic. She has also been attacked by TB."

In the italicized bold expressions, ni'ndwarete (I am living with HIV) and nigo agonseeria (will divorce me), show correspondence between a person living with HIV and a divorcee. The conceptual mapping can be expressed as A PERSON LIVING WITH HIV IS A DIVORCEE.

Another HIV testing counsellor recounted a case of a person living with HIV who had difficulties disclosing her status to her spouse for fear of the consequences. The counsellor narrates:

\section{TEXT 3}

"A 38-year-old woman tested positive for HIV in 2012 and was put on ART. She has never disclosed her status to her husband. All the while, she has been taking her medication under cover. Recently, we conducted a family testing exercise where she asked the HTS providers not to come to their home. On a separate occasion, the husband visited the hospital for medical check-up. He was tested for HIV as per the MoH policy but was found to be HIV negative. The woman said: o'mosacha o'ne amanye ng'a ni'ndwarete, ni'go a'kong'anekera mamincha y'okogania kwane. (If my husband knows that I am living with HIV/Aids, he will disclose it to people against my wish).

In the italicized words, o'mosacha o'ne a'manye ng'a ni'ndwarete, (my husband knows that I am living with HIV), ni'go a'kong'anekera mamincha y'okogania kwane (he will disclose my status and shame me against my wish). The ontological correspondence emerging is a PERSON LIVING WITH HIV IS A PUBLIC SHAME.

Another form of stigma is where a person living with HIV opts for care services in far-flung areas leaving facilities in close proximity to where they live and/or work. In a focus group discussion, an HIV testing services counsellor said the following about a client:

\section{TEXT 4}

"A 59-year old male soldier in the KDF travels all the way from West Pokot which is over $400 \mathrm{~km}$ away to this facility for ART. He has been doing this for the last five years. When I asked him why he cannot transfer to a clinic near his place of work he asked me: O'boare mbokong'u ki bobwate?(What is the problem with distance?) He challenges us to say when he has ever come late or missed to pick his medication as scheduled."

The implication in the question, O'boare mbokong'u ki bobwate?(What is the problem with distance?) is that healthcare facilities offer ART services to people from far. The conceptual correspondence is a PERSON LIVING WITH HIV IS A PARIAH AT HOME.As such, they seek care support services very far from home.

\section{Judging and/or blaming PLHIV for illness}

Another way stigma manifests itself is through the avoidance of getting tested for HIV for fear of being judged or blamed. Given that HIV is taken as a deadly condition, people would rather prefer to live with it without knowing than getting tested. In a Level 5 Private Hospital in the County, a man has been living with the fear of undertaking an HIV test both for himself and for his sickly 16-year old son. In a focus group discussion, an HIV testing counsellor in the facility narrated to us the details about him:

\section{TEXT 5}

"A man brought a 16-year son with enlarged lymph nodes. He explained that the boy has been ill on an on-an-off basis. The man refused the HTS staff to test the son for HIV. He said: Mo'ise ko'renga o'momura o'yo ni'go ngw'eita. (I will commit suicide if you test this boy). When probed further, the father said he was the source of the trouble the son was going through. Because he had lost his wife through HIV-related comp- 
lications, he thought he was HIV positive and suspected the son was also positive though he had not taken a test to confirm. After rigorous counselling, the man agreed to be tested with the son. They both tested negative! He couldn't believe it."

The words Mo'ise ko'renga o'momura o'yo (if you test this boy for HIV) can be mapped onto ni'go ngw'eita (I will kill myself). Conceptually, it can be deduced that HIV TESTING IS DEATH. The perception therefore is that people will rather die than know their HIV status or that of their close relatives.

In another case reported in the same facility, the same counsellor narrated:

\section{TEXT 6}

"A mother attending the Ante Natal Clinicin this hospital was found to be HIV positive. We requested her to bring along the spouse the following day for the HIV test. She told us that when she requested the husband to go for the test, he angrily retorted: "Kwendahuko! Kwani ni mimi niko na mimba?" (Go away! Am I the one pregnant?)"

In the italicized text, there is the emerging belief among men that women are responsible for the transmission of HIV and Aids. In terms of the conceptual metaphor theorytherefore HIV AND AIDS ISA WOMEN AFFAIR. It is evident from this attitude that people are either ignorant about HIV and Aids or they are resistant to interventions that can prevent further spread. In a broader sense, there is the perception that HIV is a problem of PLHIV. This is alluded to by UNAIDS (2002, P.9) where it is noted that stigma can cause people to perceive individuals with or at risk of HIV as the other ("them"), reinforcing the feeling that HIV "couldn't happen to me."

Another form of judging or blaming a person living with HIV involves the non-infected population discriminating the infected people thereby heightening stigma and discrimination.A mentor mother in a Level 3 facility living with HIV remembers how a neighbor who was privy to her HIV status warned her friend against keeping her company:

\section{TEXT 7}

Tiga go'tara n'omonto o'bwate enyamoreo. (Stop keeping the company of someone with the disease that emaciates)

In this text, the word e'nyamoreo implies that HIV/Aids is a condition that eats up one's flesh. The conceptual correspondence therefore would be HIV IS AN EMACIATOR. This statement Tiga go'tara n'omonto o'bwate enyamoreo (Stop keeping the company of someone with the disease that emaciates) connotes that the stigma and discrimination that people living with HIV are subjected to is extended to those they associate with. Therefore, people are warned against the company of people living with HIV. Clearly, the belief that one can contract HIV by merely keeping the company of a person living with the condition is indicative of people's discriminating perceptions. This view is reinforced by Mittelberg (2007, P.34) who notes that metaphors convey the images, feelings, customs, values and thought patterns found in our cultures.

In the same facility, a peer navigator recounted how a man commented about her condition to other men when she was down with pneumonia. He is quoted to have said:

\section{TEXT 8}

"Rigwa riamobetire. Ngotiira are." (She has been pricked by a thorn. She is ascending - to Heaven)

The conceptual correspondence in this text is HIV IS A JOURNEY TO DEATH. There is a belief among the AbaGusii that once you have been pricked by a thorn, a life threatening infection can find way into the body and kill one gradually. It is therefore understood that once one contracts the HIV virus, the person would have embarked on a slow journey to death. This observation corroborates work by Nyakoe et al (2014) based on the basic metaphor HIV IS A JOURNEY TO DEATH. In the study, EkeGusii speakers perceive a seropositive individual as a traveller on an endless journey of taking ARVs or death. The perception emerges in the text above ...Ngotiira are (She is ascending to Heaven)

A 20-year-old female peer navigator in a Level 4 public health facility recounted how she faces stigma and discrimination on a daily basis. She remembers how they had gone for community based HIV and Aids campaigns and testing. She overheard a person say the following from the crowd:

\section{TEXT 9}

No'rora o'moiseke oria o'norete iga, na'bwate o'morero o'ria o'monene (Although that girl looks fat, she has that huge fire)

In this text, it can be conceptually deduced that HIV IS A HUGE FIRE. A huge fire is known to consume a body into charred remains. This destructive power of fire is compared to assumed debilitating effects of HIV and Aids. With cynical messages such as these, PLHIV may either fail to enroll for anti-retroviral therapy or, if enrolled, fail to adhere to drug taking regimen. Clearly, ad- 
herence concerns will undermine the quality of care for PLHIV.

A sex worker working as a peer navigator in an HTS clinic targeting key populations such as Sex Workers (SWs), People Who Inject Drugs (PWID), and Men who have Sex with Men (MSM) recounted a remark a person made after an encounter with a male client:

\section{TEXT 10}

"O'tachire egwayay'esitima."(He has stepped on an electric wire)

The conceptual mapping in this text can be expressed as HIV IS AN ELECTRIC CURRENT, implying that contracting HIV and Aids is a sure way to death just as happens when a person is electrocuted.The metaphor also communicates the meaning that HIV IS AN ACCIDENT. This compares withNyakoe\&Yakub (2017) who observed that HIV infection employs the accident metaphor expressed in THE HUMAN BODY IS A MACHINE metaphor and also in reference to CONTRACTING HIV IS A THORN IN THE FLESH.

A middle-aged mentor mother had always freely disclosed her HIV status duringcommunity-based HIV testing outreaches. At one such event, she narrated how she was once taken ill and hospitalized. She was diagnosed with Tuberculosis and found to be HIV positive. Her brother in-law remarked to a visitor who had come to visit her in hospital.

\section{TEXT 11}

E'ngori yamonasire. (The noose has tightened around her neck)

The conceptual correspondence in this text is summarized as HIV IS THE HANGMAN'S NOOSE. This text suggests that HIV and Aids kills rapidly the way a noose kills through strangulation. The metaphor has the effect of harming PLHIV psychologically and deflecting them from their social routines and work. Stigma arising from such metaphors can work against HIV and Aids prevention interventions (UNAIDS, 2002).

\section{PLHIV who have experienced stigma in the past}

Another form of stigma and discrimination affects PLHIV who have experienced the same before. One case in point involves a stigma-free mentor mother in an HTS clinic in a dispensary in Kisii County. She narrated to us how she experienced stigma and discrimination soon after losing her husband to HIV-related complications and how what she was told has affected her to this day.One day, her chicken strayed into a neighbour's vegetable garden and, in a fit of anger, the neighbor remarked:

\section{TEXT 12}

Tiga konya gotwerorera. A'ye n'omonto o'bwate E'nyamoreo. (Stop the pride. You have Aids)

Text 12 seems to allude that people living with HIV have no future. They only have to wait for death. In conceptual terms therefore we can say that APERSON LIVING WITH HIV IS $\mathrm{DEAD}$. The metaphor reinforces the conceptualization of stigma by UNAIDS (2002) where it is viewed as a mark of shame or discredit on PLHIV. The effects of negative metaphors on HIV and Aids have a long-term effect on PLHIV.

The same mentor-mother narrated another incident whereher cows once strayed into the neighbour's land. The neighbor ran towards them brandishing a stick shouting:

\section{TEXT 13}

E'nyamoreo ya'soire mo'gondo! E'nyamoreo ya'soire mo'gondo!

(Aids has strayed into (my) land! Aids has strayed into the (my) land!)

It can be inferred from the text that anything that is associated with a PLHIV is connected to their HIV status. Therefore, the conceptual correspondence can be expressed as: A PLHIV'S POSSESSIONS ARECONDEMNED. The implication of this text is that a PLHIV and all that they possess are isolated and discriminated against. The word E'nyamoreo negatively describes the physical effect of emaciation due to the effects of HIV. This view is corroborated by Kamau (2012) who notes that PLHIVin Central Kenya are labeled according to their physical appearance. She points out, for example, that the label "Mukingo" is used to signify "long neck" and "skinny".

Another mentor mother in the same facility narrated how she would be frowned upon anytime she wanted to say anything. In a particular incident, she had a little disagreement with a man who publicly alluded to her HIV status which continues to hurt her anytime she remembers. The man had told her:

\section{TEXT 14} in you)

Renda e'kere ime yao. (Take care of what is

In this text, one may correspond HIV and Aids to the deadliest condition that cannot allow PLHIV to think about anything else. They should not exercise their right to expression and associa- 
tion or engage in any economic activity because they are dying anyway. In other words, PLHIV are doomed.

\section{PLHIV experiencing stigma's negative effects}

This category describes how PLHIV are disadvantaged because of their HIV status. Data drawn from the study reveals that PLHIV experience stigma's negative effects in various ways. One such way is refusal by people to buy your wares. A mentor mother narrated as follows:

\section{TEXT 15}

I am a milk and vegetable vendor. When I go out to sell, those who know my HIV status cannot buy from me. I only sell to those who do not know my HIV status. I remember an insensitive remark which has hurt me to date: Ti'nkogoria monto o'rwarete e'nyamoreo mabere. A'mabere ayio nabwate e'binyinyi (I won't buy milk from a person living with HIV. The milk is contaminated.)

The conceptual correspondence in the italicized expression is WARES BELONGING TO A PERSON LIVING WITH HIV ARE INFECTED. The perception therefore is that people living with HIV can contaminate everything they handle. This therefore puts PLHIV at an economic disadvantage.

Negative effects may also take the form of mistreatment. An HTS counsellor in a Level 3 hospital in Kisii County recounted how caregivers of HIV positive orphaned children mistreat the children. The caregivers do this out of misinformation and ignorance about the nature and manifestation of HIV. The HTS counsellor narrated as follows:

\section{TEXT 16}

A caregiver of a 5-year-old orphan brought the boy for ARVs. She asked me, "Sister, when is this boy likely to die?" I assured her that the boy will live a normal life if he takes medication as required and with good nutrition. I also learnt from the caregiver that the boy is not allowed to share a bedroomwith other children. He is not allowed to share a meal or even utensils with the other children. Asking her why she does this, she told me: Tintageti bana bane banyore o'borwaire obobe. (I don't want my children to contract the bad disease).

Conceptual mapping in this text can be expressed as HIV IS CONTAGIOUS and therefore PLHIV should be quarantined if possible. A similar case involves a 21-year-old peer navigator who lost a job as a house help when her employer discovered that she was HIV positive. She narrated:

\section{TEXT 17}

One day my employer stumbled on my month's ARVs in a packet stacked under my mattress. She confronted me and asked: Nigo o'bwate boria o'bonene o'tari goteeba? Nigo o'tagete kong'itera abana? (You have the big one and you have never told us? Do you want to kill my children?). She asked me to pack and go.

Sacking a PLHIV is a serious form of discrimination which places affected people in poverty. To metaphorically imply that PLHIV can transmit the condition to another person by mere physical proximity or contact will certainly cause them psychosocial trauma which will entrench stigma.

Arising from the qualitative analysis of data, metaphors engendering stigma and discrimination are marks of shame or discredit on PLHIV. It is notable that stigma can manifest itself in a variety of ways, including ignoring the needs of a person or group to psychologically or physically harming those who are stigmatized. Failure to control development and use of stigma-instigating metaphors may jeopardize success rates envisaged in HIV and Aids programs touching on prevention, quality of care and policy. According to UNAIDS (2002), messages targeting PLHIV should be positive and devoid of blaming or stigmatizing as these can backfire by diverting people's attention to and uptake of support services.

\section{CONCLUSION}

In sum, it is logical to state that there is deep HIV and Aids-related stigma and discrimination in Kisii County. The words and expressions used to depict the condition are perhaps one of the greatest sources of stigma and discrimination. It is evident from the texts analysed in this paper that people structure their understanding and experiences of HIV and Aids through conceptual metaphors derived from what Lakoff and Johnson (1980) call sensorimotor and spatial concepts learned earlier in life. Therefore, it can be said that HIV and Aids related metaphors are founded on the cultural norms of the AbaGusii people. It is imperative that PLHIV who adhere to treatment regimen prescribed to them by professional healthcare providers can live normal lives. The paper recommends the County and implementing partners to develop refutational messages and counter metaphors which deny that HIV and Aids are necessarily death sentences. Behaviour change communication models can be used to unlearn the metaphors based on 
cultural myths and misinformation and learning well-crafted messages based on success stories on HIV and Aids response.

\section{ACKNOWLEDGEMENTS}

The work reported in this paper was a result of concerted efforts for which we are greatly indebted. We acknowledge the National Research Fund (NRF) under Grant Number NRF/1/ $\mathrm{MMC} / 308$ for funding the project which generated data, part of which constituted this paper. We are also indebted to healthcare personnel and their clients in selected facilities who were instrumental during data collection.

\section{REFERENCES}

Bolognesi, M. (2017). Conceptual metaphors and metaphoric expressions in images. In Baicchi, $A$ and Pinelli, E. (Eds). Cognitive Modelling in Language and Discourse Across Cultures. UK: Cambridge Scholars Publishing.

Cresswell J. W., \& Plano Clark V. L. (2011). Designing and Conducting Mixed Method Research. Thousand Oaks, CA: 2nd Sage.

data. In Gonzalez-Marquez, Monica \&Mittelberg, I. (Eds.). Methods in Cognitive Linguistics. Amsterdam: John Benjamins Publishing Company.

DeJonckheere, M., \& Vaughn, L.M. (2019). Semistructured interviewing in primary care research: A balance of relationship and rigour. Family Health and Community Medicine, 7, 1-8. Doi:10.1136/fmch-2018-000057.

Feyissa, G.T., Abebe, L., Germa, E., \& Woldie, M. (2012). Stigma and discrimination among people living with HIV by healthcare providers, Southwest Ethiopia. BMC Public Health, 12, 522.

Forceville, C. (2002). Further thoughts on delimitating pictorial metaphor. Theoriaet Historia Scientiarum, 6, 213-227.

Forceville, C. (2013). Searching for one's identity is looking for a home in animation film. In: M. J. PinárSanz (Ed.), Multimodality and Cognitive Linguistics issue of Review of Cognitive Linguistics, 11(2), 250-268.

Guthrie, M. (1964). The Classification of Bantu Languages. London: Dawnson's Pall Mall Publishers.

Kamau, M.N. (2012). AIDS stigma and discrimination in public schools: A case study of HIV-positive children in Kenya. Monograph. The University of Western Ontario.

Lakoff, G., E Johnson, M. (2008). Metaphors We Live By. Chicago: University of Chicago Press.

McGlone, M. S. (2007). What is the explanatory value of a conceptual metaphor? Language $\mathcal{E}$ Communication, 27, 109-126.
Mittelberg, I. (2007). Methods for multimodality: One way of working with speech and gesture

MoH. (2012). National Guidelines for PMTCT Peer Education and Psychosocial Support in Kenya: The Kenya Mentor Mother Program. Nairobi: National AIDS and STI Control Program (NASCOP).

MoH. (2014). The National HIV and Aids Stigma and Discrimination Report: Summary Report. Nairobi: National Aids Control Council.

Ng, C., \& Koller, V. (2013). Deliberate conventional metaphor in images: The case of corporate branding discourse. Metaphor and Symbol, 28(3), 131-147.

Nyakoe, D., \& Yakub, A. (2017). Metaphorical conceptualisation of contracting HIV as an accident in Ekegusii and Aids Discourse. International Journal of Scientific Research and Innovative Technology, 4(5), 77-85.

Nyakoe, D., Oloo, P., \& Ongarora, D. (2014). Conceptualization of the seropositive using the journey metaphor in EkeGusii HIV and AIDS discourse in Kisii County, Kenya. International Journal of Academic Research in Business and Social Sciences, 4(8), 316-325.

Ochieng, N.T., Wilson, K., Derrick, C.J., \& Mukherjee, N. (2018). The Use of focus group discussion methodology: Insights from two decades of application in conservation. Methods Ecological Evolution, 9, 20-32. https://doi. org/10.1111/2041-210X.12860.

Onchoke, A., \& We, X. (2017). A cognitive analysis of woman metaphorsin Ekegusii Language. Linguistics and Literature Studies, 5(5), 344-353.

Perez-Sobrino, P. (2016). Multimodal metaphor and metonymy in advertising: A corpus-based account. Metaphor and Symbol, 31(2), 1-18.

Phillips, B., \& McQuarrie, E. (2004). Beyond visual metaphor: A new typology of visual rhetoric in advertising. Marketing Theory, 4, 113-136.

UNAIDS. (2017). Confronting Discrimination: Overcoming HIV-related Stigma in Healthcare Settings and Beyond. Geneva.

USAIDS. (2002). Behaviour Change Communication (BCC) for HIV/Aids: A Strategic Framework. USA: Family Health International Institute for HIV/Aids.

Van Weelden, L., Maes, A., Schilperoord, J., \& Swerts, M. (2012). How object shape affects visual metaphor processing. Experimental Psychology, 59(6), 364-371.

Wamalwa E., Neyole, E., Poipoi, M., \& Bitok, M. (2015). Knowledge levels and gaps on preventing HIV transmission among people living with HIV in Kisii County, Western Kenya. Human and Social Science Research, 7(2), 030-041.

World Health Organization. (2016). Country Policy Review on Partner Notification Services. Geneva. 